This item was submitted to Loughborough's Research Repository by the author.

Items in Figshare are protected by copyright, with all rights reserved, unless otherwise indicated.

\title{
Ethnographic methodologies for construction research: knowing, practice and interventions
}

PLEASE CITE THE PUBLISHED VERSION

http://dx.doi.org/10.1080/09613218.2010.512193

\section{PUBLISHER}

(c) Taylor \& Francis Ltd

\section{VERSION}

AM (Accepted Manuscript)

\section{PUBLISHER STATEMENT}

This work is made available according to the conditions of the Creative Commons Attribution-NonCommercialNoDerivatives 4.0 International (CC BY-NC-ND 4.0) licence. Full details of this licence are available at: https://creativecommons.org/licenses/by-nc-nd/4.0/

\section{LICENCE}

CC BY-NC-ND 4.0

\section{REPOSITORY RECORD}

Pink, Sarah, Dylan Tutt, Andrew R.J. Dainty, and Alistair G.F. Gibb. 2019. "Ethnographic Methodologies for Construction Research: Knowing, Practice and Interventions”. figshare. https://hdl.handle.net/2134/17838. 


\title{
Ethnographic Methodologies for Construction Research: Knowing, Practice and Interventions ${ }^{1}$
}

\author{
Sarah Pink, Dylan Tutt, Andrew Dainty and Alistair Gibb²
}

\begin{abstract}
Ethnographic methodologies developed in social anthropology and sociology hold considerable promise for addressing practical, problem-based research concerned with the construction site. The extended researcher-engagement characteristic of ethnography reveals rich insights, yet is infrequently used to understand how work-place realities are lived out on construction sites. Moreover studies that do employ these methods are rarely reported within construction management journals. This article argues that recent innovations in ethnographic methodologies offer new routes to: posing questions; understanding work-place socialities (that is, the qualities of the social relationships that develop on construction sites); learning about forms, uses and communication of knowledge on construction sites; and turning these into meaningful recommendations. This argument is supported by examples from an interdisciplinary ethnography concerning migrant workers and communications on UK construction sites. Commissioned by the UK sector skills council ConstructionSkills, the research sought to understand how construction workers communicate with managers and each other and how they stay safe on site, with the objective of informing site health and safety strategies and the production and evaluation of training and other materials.
\end{abstract}

\section{Introduction}

The use of ethnographic approaches developed in the social sciences is slowly increasing in construction industry research. However most existing work in this area focuses on the preand post-production phases of construction. This article departs from this emphasis to offer insights into the relevance of ethnographic methodologies and their theoretical underpinnings for understanding the social and material conditions of the construction site itself. In doing so it builds on recent studies where ethnographic methodologies have been employed to understand how tacit knowledge, materials and socialities are implicated in the on-site work practices of construction workers (e.g. Strati 2003, Gherardi and Nicolini 2002, Mars 2005, Marchand 2003, 2007). These ethnographic approaches make two key advances. First they represent a departure from the dominant methodologies in construction site research, which, largely rooted within the positivist tradition, have limited researchers' abilities to grasp the meaning of social action from the perspective of the actors involved (Dainty 2008). Second, by engaging with theories of practice, knowing and aesthetics, they propose more theoretically sophisticated ways of understanding work on construction sites. Despite these developments ethnography remains an unconventional and little understood methodology in construction site research. Yet as this article demonstrates it offers a route to

\footnotetext{
${ }^{1}$ Pink, S., Tutt, D.E., Dainty, A.R.J. and Gibb, A.G. (2010) Ethnographic Methodologies for Construction Research: Knowing, Practice and Interventions. Building Research and Information, Vol.38, No.6, pp647-659. ISSN: 0961-3218.

${ }^{2}$ Professor Sarah Pink, Department of Social Sciences, Loughborough University, UK. S.pink@lboro.ac.uk Dr Dylan Tutt, Centre for Practice \& Service Improvement, Staffordshire University, UK. D.E.Tutt@staffs.ac.uk Professor Andrew Dainty, Department of Civil and Building Engineering, Loughborough University, UK. A.R.J.Dainty@lboro.ac.uk Professor Alistair Gibb, Department of Civil and Building Engineering, Loughborough University, UK. A.G.Gibb@lboro.ac.uk
} 
a deeper understanding of the social practices, relationships and knowledge that inform the ways construction workers perform on site. In doing so it provides a powerful and underutilised research tool for projects that aim to make applied interventions in actual construction processes.

This article therefore responds to the need for a more thorough application of social science theory (Bresnen, Goussevskaia and Swan 2005: 487) and methodology to construction industry research. While there is a stronger history of the use of such approaches to understand buildings, and the work practices of construction industry professionals such as designers (Yaneva 2009, Whyte et al. 2007), the focus on what actually happens on construction sites themselves is more limited. This article expands the debate in three interrelated directions by: 1) exploring the application of innovative ethnography in an interdisciplinary context that interweaves anthropology, sociology and engineering to focus on construction sites; 2) using anthropological theories of knowledge to understand how construction workers, and ethnographers themselves know 'in practice' onsite - thus reflecting on the methodology itself; 3) situating ethnographic practice at an intersection between academic and applied construction industry research.

To support this discussion we refer to both existing literatures and two examples drawn from an interdisciplinary applied ethnography, developed with and for ConstructionSkills. This research investigated communication between and amongst non/low English-speaking construction workers and English-speaking site managers. The study sought to better understand how such workers were integrated into the sector and managed their personal health and safety on a day-to-day basis with the objective of using these insights to inform and evaluate the production of training and other materials.

\section{Ethnography: principles and practices}

Ethnography is an established research methodology, used in multiple field-sites and to respond to diverse questions. It is a methodology that develops in practice (see Pink 2009) and is best defined through a consideration of how it is practiced. Karen O'Reilly usefully defines ethnography as minimally: 'iterative-inductive research (that evolves in design through the study), drawing on a family of methods, involving direct and sustained contact with human agents, within the context of their daily lives (and cultures), watching what happens, listening to what is said, asking questions, and producing a richly written account that respects the irreducibility of human experience, that acknowledges the role of theory as well as the researcher's own role and that views humans as part object/part subject' (2005: 3).

'Classic' approaches (e.g. Atkinson et al 2007) advocate that ethnographers spend extended periods of time (perhaps a year or two) with the people they are researching. This would involve observing behaviours, participating in activities, writing extensive notes, interviewing and reflecting on one's own role in this research process. Such conventional long-term ethnography can yield in-depth results, yet is costly in researcher time (for fieldwork and analysis), therefore for applied research its time-scales are often not viable (Pink 2005). However more recent innovative approaches to doing ethnography have sought alternative routes to understanding. They employ participatory and collaborative (rather than observational and distanced) photographic, video-based and other techniques. These are designed to enable ethnographers to 'share' or better understand other people's experiences, and to generate closer and empathetic understandings of these experiences in contexts of analysis and dissemination (see Pink 2007, 2009). Newer ethnographic approaches also recognise that long-term fieldwork in one location for extended periods might not be viable in research that investigates the relatedness of things and people in different localities or movements between and within places (consider the limitations of, for example, the temporal nature of construction projects and the involvement of their actors). They are likewise more accommodating of project timescales that are limited by industry 
deadlines and/or budgets. In such contexts ethnographic techniques are tailored to the possibilities and limitations of such frames. Indeed the migrant worker study discussed here represented such a contemporary, innovative, rather than 'classic', construction site ethnography.

\section{Ethnography in the construction industry}

One of the earliest ethnographic accounts of construction site life is Sykes (1969a; 1969b) discussion of a participant observation study in which he examined patterns of group behaviour amongst workers on the construction of a hydro-electric plant in Scotland. Sykes lived with the workers for five weeks and made 'frequent visits to the bars in two adjacent camps' to check the representativeness of his observations in the camp he worked in. He supplemented ethnographic observations by interviewing workers and other stakeholders. Sykes' participant observation ended when he was hospitalised following an accident. Although his work revealed the importance of understanding the social relations of men working in such transient circumstances, since then similar ethnographic accounts have been relatively rare. In this section selected existing examples are reviewed (others include Bresnen 1988, Mars 2005, Paap 2006, Rooke and Clark 2005). While each case is contingent on specific social, material, political, institutional and further contexts, they reveal a set of key themes and interests that can inform a wider analytical framework. The examples selected also form a basis from which to build an approach to ethnography that interweaves theories of learning, knowing and ethnographic practice. This is in contrast to ethnomethodological approaches to ethnography in the construction industry, such as the 'strong' 'unique adequacy requirement' as outlined by by Rooke, Seymour and Fellow's (2002), which does not accept the use of theoretical principles external to the research setting for its description. Whereas the approach of Rooke et al (2002) proposes isolating theory from the research setting, the alternative approach taken here suggests that it is impossible to undertake theory-free ethnography. Rather the essential criteria is that the researcher retains a reflexive awareness of how her or his work is informed by theory and a self-consciously considers how theory and practice remain in dialogue throughout the ethnographic process.

In an ethnographic study of safety on an Italian building site Silvia Gherardi and Davide Nicolini examine how 'building site novices are socialized in the community of practices and how, within this process, the competence relative to safety and danger is learnt' (2002: 198). With this aim the researcher accompanied a trainee on a restoration manager's course on small to medium sized building companies. The notion of apprenticeship was followed through both methodologically and substantively, focussing on the apprentice's learning process by shadowing him learning on-site skills. The researcher was both engaged in learning himself and acted as an assistant to the research participant (2002: 199). Gherardi and Nicolini's work demonstrates how significant insights can emerge from such forms of engagement with learning on construction sites. Arguing that learning and knowing about safety are inseparable from actual practice, they suggest that learning happens on building sites in ways that 'differ markedly from the received wisdom about the process of workplace learning which informs the way safety is promoted and "taught" in the building industry in Italy and around the world' (2002: 217).

Antonio Strati examined safe working practices with a focus on aesthetics. The ethnography he discusses developed serendipitously. While observing a meeting in an organisation, he was distracted by a group of roofers working on nearby building. He was simultaneously 'struck by the workmen's apparent disregard for safety systems' and the 'surprising agility' of one plump workman (Strati 2003: 57). Strati then held a series of lunchtime conversations with the roofers, discussing how work is done on the roof and how it is learnt (2003: 60). Although the workers' answered his questions to some extent, they could not answer them fully because 'the lessons taught to the male novice were grounded 
on something that was vague, unexpressed, and unknown' (2003: 61). To represent this tacit knowledge Strati invites readers to imagine themselves into the embodied work practices and aesthetic knowing of the workers as represented in his descriptions (2003: 63-4). Like the apprenticeship approach, Strati's use of observation and interviews sought to understand how workers learn in practice. It investigates the unsaid, and innovatively offers readers routes through which to try to comprehend the unsayable.

The social anthropologist Trevor Marchand has undertaken long-term ethnography with traditional builders in Sana'a, Yemen. His research was 'concerned with the expert knowledge possessed by skilled craftsmen' and involved his working with the builders as a labourer to examine 'the manner in which trade knowledge is acquired, transmitted and controlled by a specialised team of mosque builders' (2003: 31). Marchand points out how for the Sana'a, building knowledge which is learnt through apprenticeship (2003: 34) is not easily articulated verbally: 'the content of the master builder's knowledge eludes any (coherent) verbalised articulation largely as a consequence of the way in which his expertise is transferred, acquired and possessed by apprentices' (2003: 35). This knowledge is transmitted in practice, and not by 'mastering a formulaic recipe of procedures' (2003: 36). Reflecting on his experience as an apprentice he comments how: 'my knowing how to carve a brick of type "A", which I learned at the building site through mimicry and practice, is not entirely translatable into a propositionally constituted form of knowledge. Much of the practical experience that constitutes the knowing how eludes being "fixed" by language, and is therefore filtered out in descriptions' (2003: 43). For Marchand this raises the question of why the builders 'cannot explain what they know', and on how such knowledge is constituted (2003: 44, original italics).

The insights from these existing ethnographies suggest that in construction work skilled practices are not simply learnt, transmitted, modified or adapted through the verbal communication of objectified knowledge. Indeed, neither workers nor ethnographers can necessarily articulate verbally either what they know or how they know it. Following anthropological thought on this topic (see Ingold 2000), skills transmission happens in practice and the ways of knowing that skills embody are located in practice. This raises questions about how the ethnographer can come to know what others know. The ethnographies discussed above demonstrate two possible approaches: the ethnographer observing work in practice and asking questions later; or the ethnographer becoming an apprentice to the worker's craft, thus hoping to experience knowing akin to theirs. These practices are differentially distanced from the work practices to be analysed, yet both can offer routes to understanding that create a valid basis for proposing interventions.

These construction site ethnographies offer insights into how construction workers learn and know. They also affirm that these insights cannot be gained without direct engagements with workers as they practice their skills on site. Yet they do not elaborate on how such research findings can be harnessed for applied interventions in the construction industry, thus limiting the potential impact of such work. In what follows, approaches from applied anthropology are first reviewed to develop a framework for ethnography-based interventions that can account for the types of knowledge/knowing discussed above. This is then elaborated through examples from the migrant construction worker study to demonstrate practical applications in construction site research.

\section{Local Knowledge and Knowing in Practice}

Anthropologists of development recognise that to produce successful interventions an understanding of 'local' or 'indigenous knowledge' (IK) is required. Paul Sillitoe (2002) a leader in this field, suggests a working definition: 'Indigenous knowledge in development contexts may relate to any knowledge held more or less collectively by a population, informing understanding of the world'. The more mobile and fragmentary contexts of ethnography with construction workers do not directly correlate with the idea of IK, which is 
'community based, embedded in and conditioned by local tradition'. Yet elements of Sillitoe's definition are informative. He points out IK 'exists nowhere as a totality, there is no grand repository, and hence no coherent overall theoretical model, although it may achieve some coherence in cosmologies, rituals and symbolic discourse' and 'it is the heritage of practical everyday life, with its functional demands, and is fluid and constantly changing, being dynamic and subject to ongoing local, regional and global negotiation between people and their environments' (2002: 9). The methodological implication of Sillitoe's definition for the ethnography of the IK of construction workers is significant: to understand what construction workers know requires attention to the detail of their everyday practical activities, common beliefs, values and discourses in which this knowledge is manifested.

The IK approach has a further methodological implication for construction site research. IK is not studied simply for its own sake, but, to inform interventions. The objective of researching IK in a development context, 'is to introduce a locally informed perspective into development, to challenge the assumption that development is something outsiders have a right to impose, and to promote an appreciation of indigenous power structures and know-how' (Sillitoe 2002: 9). An IK approach can thus inform understandings of how and why understanding workers' own knowledge(s) is crucial for developing appropriate and effective social interventions on construction sites. However the introduction of IK or 'local knowledge' in applied intervention processes is not straightforward. Johan Pottier stresses 'how knowledge for development is negotiated through processes of translation' (Pottier 2003: 3) and that local knowledge cannot simply be extracted and used for scientific purposes (see Pottier 2003: 1). Local knowledge or IK is 'dynamic, diverse, sometimes contested or used euphemistically, and always socially and culturally embedded' and is also not necessarily articulated or transmitted verbally (2003: 7). These complexities resonate with theoretical and methodological questions that have preoccupied scholars across social science disciplines in recent years: how and what do people know; how do they express it, transmit it to others, learn it; and how might ethnographers access and represent such knowing/knowledge (Ingold 2000, Harris, 2007, Halstead et al 2008, Rooke \& Clark, 2005, Pink 2009).

Existing publications in the IK/local knowledge literature show how, in industrial contexts, 'local' knowledge and practice often differs from that represented in institutional codes. The case of health and safety knowledge is a good example. For instance, Alberto Arce and Eleanor Fisher note how for employees of an oil company in Wales 'At the Oilworks, the knowledge of their job provided men with the experience to devise practical ways to achieve the task at hand without necessarily following the safety regulations designed to avoid them hurting themselves' - in this case by not wearing the required gloves when working in the 'paraffin shed' (2003: 89). The migrant construction worker ethnography revealed similar ways of weighing up risks and time use in both individual and collective activities. In collective practices mobile phone use is one example of construction personnel (necessarily) reinterpreting and appropriating site safety 'rules'. Mobile phones are ubiquitous on construction sites and their use needs to be understood in relation to the huge variety of trade and work tasks in construction. The ethnographer quickly observed that, in practice, their use could not be easily regulated by the impracticality of a few designated 'mobile phone zones'. When exploring this in interviews, a health and safety manager for a large contractor articulated the ambiguity surrounding their use: 'If you're using your mobile phone on site we tell people not to do it, but then we're not above doing it ourselves, to be honest. If there's an incident onsite then, you kind of, you want people to do it, so. I don't think we're $100 \%$ straight on whether it's right or wrong yet'. As a project manager for a large contractor explained: '[It would be] like doing a risk assessment against everyone's job and everyone's task within that job'. As the researcher observed and discussed at work breaks, one use of mobile phones involved social/collaborative showing of photographs of girlfriends, sharing jokes, videos etc. Yet, as one of the examples discussed below shows mobile phones were also used by workers for the fine coordination of safe work practices. Simultaneously they were used by contractor management to easily locate and move 
workers around sites, and for institutionally recognised safety practices. For instance, on one project workers were encouraged to phone a number printed on their helmets in cases of health and safety emergencies onsite.

The example of mobile phone use demonstrates how drawing false binaries between 'local' and 'institutional' knowledge would be misleading. As Pottier comments 'The image of two opposed knowledge "systems" does not reflect the complex and often contradictory processes that structure development at the local level' (2003: 5). Both workers and management innovated in the ambiguous space of mobile phone use regulation to create overlapping codes of practice. In other words, 'safe' mobile phone behaviour onsite was something that was negotiated and learnt in practice. Likewise layers and types of knowledge and knowing that are at play on construction sites are interdependent and complex. It is not a question of simply arguing that the construction workers know more about how to communicate and create a safe working environment than do the health and safety managers. Rather it is one of identifying, acknowledging and exploring how to make the most of the safe practices they have developed through well considered, and welcome, workplace interventions.

The IK/local knowledge approach thus offers a route to understanding some of the complexities of how workers' knowledge is integral to the (safe) achievement of everyday workplace practices. However, to apply this approach to the specific context of the construction industry other frameworks are also needed. For instance, for the Oilworks example discussed by Arce and Fisher, most employees were from the local 'community'. Some families had worked at the Oilworks for three generations and considered employment there a 'job for life' (2003: 88). Employment in the British construction industry is fundamentally different. Some groups regularly work together, and the socialities (on-site and off-site) that construction work involves are essential to some work practice. Yet these social and workplace continuities are not universal as most projects are characterised as temporary multiple organizations (c.f. Cherns and Bryant, 1984). Construction work often involves workers moving from site to site, between different workgroups, and for many migrant workers between countries. Workers may be transported to sites in vans or buses, on a daily basis by a contractor or agency. They may neither work where they live nor live where they work. The materiality of construction sites constantly changes in conspicuous ways as building stages are completed (Bresnen 1988). Workers might work on sites for short periods, changing not only physical location as they move, but also institutional frames as they transfer to a new company (even if with the same agency) with new colleagues. While some long-term work groups who developed specific co-working practices and understandings were found, for many construction tasks the composition of gangs changes throughout the course of a week or day. In these dynamic trades the activities, and work teams are engaged in, can vary from moment to moment. It is rare for a construction worker to hold a stable job in both senses, of having a permanent contract and, when working, being in a fairly stable team/working unit. For example, a Romanian Health and Safety Manager working for a large contractor, explained in an interview how what the ethnographer saw was not what he knew: 'you [the researcher] see them working together in one place - they're not like that'. He elaborated on the working patterns of his team of sixteen Romanian workers:

I've got a dumper driver, okay. He drives from sites all over the place... I've got two machine drivers, Romanians... You've got two or three in a gang which is low skilled - the cutting, breaking concrete. Even if there are twenty [Romanian workers] on the same site, they're working fairly isolated.

In this context the question of what IK or local knowledge is becomes further complicated because workers are acting in material, social, institutional and aesthetic environments - as 
is the case for construction sites - that are continually shifting. To resolve the indeterminacy of 'the local' as a repository of knowledge in this context, the discussion below focuses instead on the way knowledge (or knowing) is located in practice.

\section{'Knowing in practice' and knowing what others know}

Recent literatures in anthropology (e.g. Harris 2007, Halstead et al 2008) and organization studies (Nicolini, Gherardi and Yanow 2003) represent a current concern with processes of knowing, learning, and how ethnographers might come to know what and how other people know. Coinciding with what has been referred to as a 'practice turn' (Schatzki et al 2001) in contemporary social sciences, several of the works in these volumes focus on how embodied knowledge is embedded in actual practices. Practice approaches moreover offer a convenient framework through which to develop an analysis of a material environment such as that of the construction site in assuming 'the social is a field of embodied, materially interwoven practices centrally organised around shared practical understandings' (Schatzki 2001: 3). Of particular relevance here is the concept of 'knowing' developed by Etienne Wenger. Wenger proposes 'knowing is defined only in the context of specific practices, where it arises out of the combination of a regime of competence and an experience of meaning' (1998: 142). His proposition should be understood in terms of his concept of 'Communities of Practice' (1998), which is highly influential in organisation studies, including work on the construction industry (Gherardi and Nicolini 2003), and workplace studies and CSCW (e.g. Jordan, 1996). Wenger understands 'learning as social participation' and, as he puts it, '[p]articipation here refers not just to local events of engagement in certain activities but to a more encompassing process of being active participants in the practices of social communities and constructing identities in relation to these communities' (1998: 4).

In researching the construction industry, 'local knowledge' is difficult to pin-point given that the concept of a locality is itself difficult to apply to the realities of construction sites. The notion of knowing in practice suggests understanding work-practice knowing as knowing through regular interactions with specific other persons (other workers and managers), materialities (tools, equipment, materials), institutions (companies, agencies) and discourses. It thus involves interacting in a recognisable environment that might be reconstituted in rather different configurations for different jobs, rather than in a determined locality. An understanding of construction knowledge as a form of 'knowing in practice' nevertheless directly supports the methodological approach developed in the IK literature discussed above. There is therefore a situated body of construction knowing, experienced and mobilised in practice. Such 'knowing' is not a fixed body of knowledge, it is not attached to one locality, but it is learnt, adapted, modified, and engaged in practice by group(s) of practitioners who are in frequent contact with each other. For example, a gang of curtain wall installers whom the project ethnographer observed and had discussions with on site, spoke an adaptable language (including English and Italian as well as different East European languages). This involved the tailoring of communication content to identify, address and communicate with specific workers in the team. This is just part of their established team dynamics; the well-rehearsed communication practices and working relationships built up, alongside their learning of the affordances of shared tools and materials of the trade, through months, and in most cases years, of curtain wall fixing together on different construction sites.

For the case of the construction industry, while knowing is contingent and based in practice and work is often fragmented and involves much mobility, there are simultaneously continuities in knowing across workers, sites and time. These continuities do not correlate directly with the extent of coherence implied by the 'mutual engagement ... joint enterprise and ... shared repertoire' that Wenger's (1998) model outlines (Martin 2005: 143). Indeed as for bi-lingual co-workers in other contexts the intricacies of a multi-lingual construction industry as a whole call for 'more complex theories of social learning' (Martin 2005: 156). Yet 
were there not sufficient continuities the industry would not be able to function. Thus understanding the industry as something akin to a community of practice, in which intensities of social learning (such as the case of the curtain wall glazers) produce safe working practices, provided both units for ethnographic analysis and enabled the applied task: to sufficiently understand the ways of knowing involved to be able to recommend how identified practices, and/or the principles through which they are performed, might be recognised as 'good' practices. Studying construction work 'in practice', thus revealed some of the local practices and knowledge at 'ground level'. These practices and knowledge may have been excluded - or remained below the horizon of notice - in both industry definitions of safe practice and in research that does not engage with workers ethnographically in the moments when knowing is enacted in practice.

Generalising from this, the strength of an ethnographic approach is that it allows researchers to understand how otherwise 'invisible' ways of knowing are engaged in everyday and essential construction work practices. However, this also has further practical relevance. In the following section two examples from the health and safety research project are outlined to demonstrate how the insights drawn from ethnographic methods can inform applied recommendations for improving practice. They have been included to illuminate the discussion around communication of knowledge, learning in practice, and ethnographic methodologies, as well as to convey the types of insights which can emerge from interdisciplinary applied ethnography.

\section{Ethnography on site}

\section{The context}

The research responded to a context where some commentators had attributed recent increases in fatalities on construction sites to migrant workers' supposed use of less safe working procedures and low English language skills (Owen 2007). Yet existing evidence on this question is itself ambiguous. There is no universally accepted figure for the number of migrant workers in Britain. Estimates for the number of migrant workers in the construction sector range from $2.4 \%$ to $8 \%$ and statistics on their nationality or migration status are limited and uneven. Information compiled by the Health and Safety Executive (HSE) since 2002/3 indicates migrant deaths have risen six-fold in 6 years (from 2 to 12), increasing the proportion of migrant worker deaths to the total number of construction worker deaths from $2.9 \%$ (in $2002 / 3$ ) to $16.7 \%$ in (2007/8). A small scale ethnographic project could not determine general causes of fatalities on construction sites on that scale. Rather it could address the issue from another direction, through the question of how health and safety is managed by migrant construction workers themselves in this culturally diverse context. The existing evidence suggested that everyday practices on construction sites must also involve countless examples of successful communications and safe working practices involving migrant workers. Thus the project aimed to examine examples of and patterns in successful communication to avoid health and safety problems and advance these as a basis for the development of improved heath and safety measures. This approach sought to ensure that the communication models developed will be compatible with existing practices and therefore easier for construction workers to adopt.

The academics leading the project brought interdisciplinary expertise in the construction industry, sociology and anthropology. The researcher had a background in sociology and applied workplace research using ethnographic and visual methods, and a highly established applied anthropologist, with experience of working in the construction industry, acted as a peer reviewer. This intersection between industry-specific knowledge and experience, methodological and theoretical approaches from social sciences, and 
hands-on experience of doing (visual) ethnographic research in organisations provided a robust platform from which to critically examine the insights emerging from this work.

The researcher focussed on and repeatedly visited five construction sites which permitted different kinds of access, ranging from regularly shadowing workers onsite, to being limited to site inductions and canteens, or pre-arranged interviews. The research was overt in that fieldwork onsite initially had to be organised from the 'top-down'. Meetings and interviews were arranged with site managers and health and safety directors and the on-site researcher role was transparent. Indeed, a requirement for access on site was often that the researcher should go through the site induction process. Over time, through introductions and conversations onsite and in the canteen (including regular chats about the potential of young Polish goalkeepers at the 'Arsenal' canteen table on one London site!), relationships developed with workers, and some of these became key figures ('gatekeepers') who were invaluable for repeat visits, and sustained participant observation, as the cases will illustrate. Nevertheless, even under these circumstances, researching migrant workers' experiences in the construction industry was methodologically and emotionally challenging since although interviews and time spent with workers was cleared with management first, the researcher's presence could still cause/encounter problems or tensions onsite. The ethnographer found that without him first spending time with a team, his unfamiliar face observing or, on occasions, note-talking could very easily be presumed to be on the look out for rule-breaking or health and safety incursions. The case of a worker on an adjacent tower block who, conscious of the researcher's gaze, became distracted from his work and continued to apply additional layers of PPE (Personal Protective Equipment) is a pertinent example., Ethnographic encounters also create close relationships through which researchers appreciate the perspectives of participants and, when these are at odds on site, as the researcher found, he could feel personally compromised.

In the following sections, two examples (written as first person narratives in italicised text) are discussed in order to contrast fieldwork encounters in site inductions with those of an inquiry into how knowing-in-practice was lived out by a team of curtain wall installers. These different approaches provided access both to construction workers' performances of knowing (in the team of curtain wall installers) and performances of not knowing (for migrant workers aiming to get through site inductions). They also informed recommendations to the sponsor as is discussed below.

\section{Observing and asking: learning about knowing in practice}

'Hanging around' with a team of curtain wallers, the fieldworker soon came to form relationships that enabled his ethnographic work. He describes how:

A Russian worker, Viktor, became the key contact point and 'gatekeeper' to my accessing a naturalistic study of the curtain walling team at work and, inevitably, the person with whom I became closest. In a similar vein to the way he quickly grasped the type of information and experiences which most interested us during participant observation, Viktor proved just as pivotal in helping to put other workers at ease with my presence. This included him introducing me to a (reserved) Bulgarian colleague in the team, and occasionally 'vouching' for me in front of workers by reminding them of past occasions when we had met onsite (without incident or repercussion). This was often done by joking in front of the team about details of the gang's habits he had told me about, or that I was secretly hired as a government spy! 
The fieldworker's work with Viktor and his team developed in response to our research questions. Yet the questions were answered in ways that demonstrate the quality, fine detail and serendipity often associated with ethnographic research.

...Viktor explains to me that he is employed directly with the subcontractor, and that his team is made up not only of Polish, Russian workers and Italian management, but also Lithuanians, Bulgarians workers and English supervisors. Viktor is based on the twelfth floor and spends a lot of the time leaning over the side to get a good view of the workers at ground level and, as I join him, he suggests I turn my hard-hat around like his, for a tighter fit and a better view. After answering a few of my questions, Viktor starts to volunteer descriptions of what he is doing and suddenly a world of communication channels, hidden from a lay observer like myself, come into closer focus. After a short exchange over mobile phone, through a small earphone and microphone (which I had failed to notice before), Viktor explains that he is communicating with workers on the floors directly above and below him, who are not visible. 'Did you see the hand signals?' Viktor asks after a suspended window panel is guided upwards. When Viktor, up on the twelfth floor, shouts key phrases back and forth to the workers on the ground, I ask him what was said. 'I can tell you what I said, but it was in many languages', he answers. As I look back puzzled, Viktor explains that 'we've got our own language' - mixing words and phrases from different East-European Languages depending on who is being addressed...

During my time on the twelfth floor, I asked to take several pictures of what Viktor could see, and who he could communicate with, while he was at work. Noticing my awkwardness and reluctance to lean over the edge - with no head for heights - Viktor took a photograph himself, picking out the relevant workers in his network of communication from the twelfth floor. I created an annotated map of the curtain wall glazers' ongoing work, and I used these images as a 'visual prompt' to help glean some of the other workers' (contrasting) understandings of the roles and coordination of tasks within the work-at-hand. For example, using the annotated images I asked the Section Manager (for the large contractor) on the external envelope of the building to talk through his version of the tasks pictured and to identify the other personnel in the photographs. In his capacity as a manager, he identified a major function of the dialogue between twelfth floor workers and the supervisor at ground level as being to maintain a clearance zone.

Thus ethnography involves being there, to explore how tasks are performed in practice and how people know what to do in practice. Viktor described how the team had evolved 'our own language' - a conglomerate of communication methods: a mix of different languages, gestures, simple hand signals and mobile phone links which together coordinated a complex task safely. Once Viktor alerted him to its existence, the fieldworker could perceive how initially invisible flows of communications and material objects were coordinated in ways that ensure workers' safety. Here the use of mobile phone was revealed as part of the finegrained coordination of the work-at-hand. This also shows how onsite working and social practices could be forged through the appropriation of the same technology. He thus learned about the forms of knowing in practice that were fundamental to the shared activities of this community of practice by seeking to understand the workers' experiences from their perspective. By taking the photographs himself, Viktor could show the fieldworker the situation as he saw it, from a physical location where he felt comfortable, but the fieldworker did not. These ethnographic photographs then had a further role, when used in interviews with others, which starts to illuminate the opportunistic and adaptable nature of ethnographic research in practice, which is expanded on elsewhere (see Tutt et al., forthcoming).

This ethnographic encounter provided insights into how ways of knowing and communicating that keep migrant workers safe on site are embedded in shared work practices - in a type of community of practice. It was only by investigating different 
perspectives on them that the ethnographer could 'see' the invisible routes through which communications and materials safely flowed. These ways of knowing in practice are simultaneously industry specific and particular to that group and the task in hand. As the group moves to other jobs and perhaps is split, they will be adapted. Importantly the ways of knowing and communicating employed by this group could not have been learnt without the ethnographer's engagement with their work as it was performed.

\section{Induction Research: the performance of not knowing}

Effective training is considered an essential part of improving health and safety performance in construction and it is critical that all new construction site operatives, including migrant workers, receive adequate induction training before they begin work, to step onsite with high standards of health and safety. Yet, while in informal interviews the health and safety directors presented contractors' strategies designed to improve site induction practices, the reality of everyday practice of site induction was often unrecognisable from this.

...We join the researcher on a site induction on a large contractor project in Northern England. With the inductees assembled in the room - eight seated and two standing because of a lack of chairs - the inductor (a supervisor) interrupts his introduction to take a mobile phone call. The H\&S manager onsite explains that "the induction is shared between the whole team. We've got a rota. So there's probably six of us, maybe seven, eight. So we do it on a daily rota". Today is the turn of a working supervisor whose competing demands - of coordinating tasks up on the twelfth floor of the site - make his mobile phone an essential resource. The inductor starts to play a HSE DVD on the responsibilities of safe working, which uses the example of a worker at height and the dangers of not ensuring secure working platform and edge protection after, ironically, being distracted by a mobile phone call.

After starting playback, the inductor hands two-sided forms (security and medical) out around the table, with the details needed for work onsite to be filled in while the DVD plays. I am conscious that the person whom I'm sat beside is looking at me while I fill in the form. He has, in fact, been waiting for me to finish the form and gestures towards my pen. I ask him if he wants to borrow it and he answers "yes". In discussion later, I find he is Polish and has little spoken English language skills. Alongside his limited comprehension of the DVD with attention split or focused on the form - and cautious of engaging in conversation, the worker was also waiting for the right moment to borrow a pen in order to fulfil the task...

Site inductions are clearly a critical point for the communication of health and safety information between management and the workforce. Thus they were a logical area for the research. Nevertheless the ethnographic study quickly dismantled any preconceptions of this process being a linear or simple transfer of knowledge which can be achieved just by supplying and updating induction material and resources. For example, the research indicates that it is not uncommon for two-page work and medical forms to be handed out for completion during the playing of an induction video and/or the presentation of site specific health and safety information. This splits the attention (particularly) of inductees who may not have English as a first language.

To gain a deeper qualitative understanding of the site induction process, and the issues underpinning failures to communicate health and safety information onsite, the fieldworker experienced induction multiple times at construction sites (including large national and global contractors, privately owned, and smaller construction firms) around the UK. These were delivered by site managers, health and safety managers/directors, trades 
union reps (in health and safety roles), qualified supervisors and trainees etc. within different time-frames, who put different emphases on (and contents into) their site inductions. When possible he also gathered different people's perspectives of the same occurrence or notable action during an induction, through participant observation before/after/during the site induction and in/formal interviews with migrant and UK workers, induction conveners and health and safety managers.

The qualitative methods needed to be flexible and sensitive to the issues and pressures of working on a construction site. For instance, arranging interviews with participants immediately after induction was particularly difficult, and largely inappropriate, since workers were starting their new job, meeting supervisors, orientating themselves to site etc. However where workers were instructed to wait in the induction room to be assigned to their appropriate supervisors/location onsite, such moments proved particularly useful points for contact with the workers. This opportunistic research also posed difficult ethical dilemmas, which needed to be constantly questioned and assessed. For instance, while access to research on sites was arranged 'top-down' through contractor management, this did not equate with workers and management always being aware of the researcher's role. In the context of inductions when events move quickly, the researcher had to make contingent decisions as to when remain silent, be selective, or announce their identity to an entire induction room.

Participant observation in site inductions 'on the ground' frequently revealed that vulnerable workers, with low-level understanding and communication of English language, were (at least initially) slipping through inductions unnoticed. One example is that of head nodding. Consider the cautionary account by this project manager, working on a large contractor project in London, of a failure to engage with inductees:

It's interesting when you do inductions and you're told by a supervisor, sometimes, that you know "okay, put them all through" - and l've done a lot of inductions - you sit there and you've got people nodding, and then you say "did you understand that" and everyone nods, and then when you come round and you actually talk to the individual people - which I always do in inductions - you find that people can't speak English. You [would] then have to finish the induction, go and find a supervisor, bring them back in, bring in the interpreter, redo the induction for those people.

In practice, site induction can involve temporally striking a balance between 'putting them all through' quickly and efficiently, and of wasting time by having to re-do (and have translated) the induction for workers, as articulated in the above quote. The worst case scenario is of not picking up the communication issue at all, and failing to communicate critical health and safety messages.

Indeed the example is not exclusive to this ethnography: reporting on a study in which they interviewed 200 migrant workers in the UK, McKay et al (2006) quote this migrant worker's response:

[T] hey're [the employers] not expecting sometimes people coming with one month in the country, with so poor English that they barely can understand what he's going on about, but they're smart enough to know when to nod, they see their friends signing, and they're signing, induction is done, he starts working (McKay Craw \& Chopra, 2006: 176). 
During turn-taking in talk, head nods can be used to show alignment and indicate understanding which can contribute towards confusing/mediating whether the 'message' has been received. Migrant workers encountered in our research used similar tactics which we could put into richer context by spending time and talking with workers away from the induction room about their fears and motivations behind such practices. For instance, Artur, a Polish ganger, explained his reasons for concealing his difficulty in understanding, and not asking questions, in terms of the shame of being the only inductee to do so: "When you are in some group... I don't wanna [be] asking er, and everybody looking for you, you know'.

While the fieldworker's experiences of research with the curtain wallers' gang enabled him to 'see' invisible communications and ways of knowing, his experience of inductions revealed rather different types of knowing. Here he learned how migrant workers 'get through' induction by knowing, for instance when to nod, to copy a form and ask for a pen, and also the feelings of shame, and the contingency of needing the job, that motivated these practices. Again this was a method of intercultural communication, learnt in practice, but one that would be more likely to lead to workers not engaging with institutional health and safety policies.

\section{Recommendations derived from the study}

The situated nature of ethnography need not preclude the generation of recommendations for informing practice, so long as they can be appropriated in ways that reflect the nuances of the contexts in which they are subsequently applied. As such, care was taken to avoid the imposition of prescriptive or normative advice, but to highlight pertinent insights or areas of promising practice. These offered fresh perspectives on how health and safety might be improved in the future.

As the accounts above reveal, forms of knowing in practice were fundamental to the shared work practices that kept workers safe. Thus, key to the recommendations was the need to recognise the existing communication channels through which migrant workers enact safe working. Attempts to develop a culture of healthy and safe working should embrace and compliment such practices rather than seek to displace them. Such a recommendation runs counter to the health and safety orthodoxy, which tends to focus on the standardisation of safe working practices rather than on the acknowledgement and interweaving of existing practice. Interventions to achieve this include methods of visibly rewarding safe practices in teamwork, and in doing so making examples of good practice available through appropriate and accessible routes on site.

A second example of how a recommendation emerged from the ethnographic study focuses on how informal practices were found to influence safer working through the recognition of the translator/interpreter role. Either special status or enhanced remuneration, were given in an attempt to acknowledge the complementary role that unqualified but linguistically skilled native language speakers played as translators and interpreters on site, which enabled health and safety communications. The ethnographic insights also revealed that formal recognition would require appropriate regulation in order to recognise the competency of those fulfilling such a role. Thus, a supporting recommendation was to set up appropriate workplace based methods to assess and develop language translator and interpreter skills amongst migrant workers. The aim here is to encourage the more widespread acknowledgement of the translator/interpreter function as an enabler of safe working practices in a broader range of contexts.

A third recommendation concerns the induction process, which currently conflates the very different requirements of training and briefing to the detriment of both functions. The ethnographic study revealed the limitations of such practices for conveying complex health and safety information and the inadequacy of standardised practices and video-based media. There was little opportunity to establish whether the desired learning outcomes had 
been achieved, or to overcome the stigma attached to the open discussion of risks and hazards. To overcome these limits it was recommended that there should be: a separation of the briefing function; the use of multiple media to convey such information; formal recognition of the role of interpreters in induction sessions; and acknowledged involvement of migrant workers in actively engaging with the promotion of safe working practices. Whereas standardised inductions tend to offer abstract encounters with construction sites, a closer and more practical engagement with the specifics of particular sites was suggested. As with other proposals derived from the ethnographic study, the approaches recommended should accord with the individual requirements of the site, rather than being based on standardised practice. However, it is common with ethnographic approaches that they not only suggest solutions but also identify further questions. Therefore a key recommendation was that in order to model new methods for induction more specifically further detailed ethnographic research should be undertaken with this in mind.

\section{Discussion: ethnography in applied construction research}

Ethnography is a serendipitous craft: ethnographers often expect to learn precisely when they are least expecting to. However ethnographic research is by no means hit-and-miss. Rather, a good ethnographer immerses her or himself in the types of deep learning situations described above - where what is learned goes beyond what could be said in an interview and can only be known by being there, as events unfold. Ethnographic research also entails systematically following a research agenda, seeking out answers to questions posed (even if the answers sometimes invite new questions). The existing literatures reviewed and the examples presented demonstrate on-site ways of knowing and communicating in practice that involve tacit and unspoken knowledge and performance that can cross linguistic and cultural boundaries. Through ethnographic engagements in and with these practices fieldworkers can dismantle the facades that obscure different levels of IK/local knowledge as practiced in 'communities of practice'.

The migrant worker study discussed in this paper had an applied dimension and was interdisciplinary involving inputs from social sciences and engineering at all stages. It used innovative approaches to ethnography, which were both appropriate to the complex and shifting context of the construction site and to the demands of applied research. The study demonstrates that there are practical implications and consequences of ways of learning (or not learning) and knowing in practice for on-site health and safety. Such ethnographic research can make visible informal (or unofficial) worlds of actions, interactions and ways of knowing that can easily slip under the industry (or official) horizon of notice. In the context of applied research, interpretations of these performances can lead to recommendations and ultimately interventions that are informed by an in depth knowledge of knowing in practice in construction sites. The examples demonstrate two routes through which this might be achieved: 1) The curtain wall glazer example shows the specificity of the ways of knowing through communication that might develop on site and to their embeddedness in particular socialities. It suggests that intersections between institutional and IK/local knowledge as they are operated in communities of practice should be further investigated and recognised as part of the way workers stay safe on construction sites; 2) The site induction example demonstrates problems inherent in current approaches to induction and led to recommendations that would engage workers in induction in new ways.

\section{Conclusion}

While 'classic' approaches to ethnography have infrequently been engaged by construction researchers, contemporary ethnographic methodologies that attend to how researchers can learn through either sharing or otherwise empathising with the experiences of construction workers are increasingly popular. In the midst of the hectic pace and pressure of 
construction site life, this small scale applied ethnographic study offered the luxury of time (with the workers), the ethnographer's eye, and the ear of management and the industry. Such closeness inevitably provides a new lens on the action and issues at stake.

Ethnographic methods are therefore compatible with both the nature of the material and social contexts of the construction site, and support the questions asked by applied research agendas within the industry. When informed by a theoretical framework for understanding construction knowledge as a shared and embodied form of 'knowing in practice', ethnographic methods can provide routes to knowing about on-site communications that go beyond what is immediately observable. For instance they can reveal: the actual effectiveness of formal visible channels of communication used for on-site induction; or how workers ensure their own safety through otherwise 'invisible' routes of communication. Thus revealing the discrepancies, between officially and unofficially constituted safe practice or safety performance on sites. While the unofficial 'knowing in practice' of the learned teamwork of the migrant curtain wallers was recognized as safe working, the official safety performance of migrant workers in inductions - where knowing and learned practice to 'get by' (and 'get to' work) constituted a risk to safety onsite.

Detailed ethnographically grounded understandings of such realities make it possible to propose viable suggestions regarding workplace interventions that might ameliorate such risks. In the spirit of the discussion in this article however, because these need to be implemented in practice, they must always be attendant to the specificities of the contexts and practices to which they are applied. The examples of recognising the importance of informal practices (with regards to the role of translators), or avoiding normative approaches to enacting health and safety (with regards to site induction) reveal the need to respond to the emergent realities of practice and to localised contexts and specificities.

\section{References}

Arce, A. and E. Fisher (2003) 'Knowledge interfaces and practices of negotiation: Cases from a women's group in Bolivia and an oil refinery in Wales' in J. Pottier, A. Bicker and P. Sillitoe (eds) Negotiating Local Knowledge, London: Pluto.

Atkinson, P., S. Delamont, W. Housley (2007) Contours of Culture: Complex Ethnography and the Ethnography of Complexity, Rowman \& Littlefield.

Bresnen, M. (1988) Insights on Site: Research into construction project organizations. In Bryman, A (ed.) Doing Research in Organizations, Routledge, London, pp34-52.

Bresnen, M., Goussevskaia, A., Swan, J., 'Editorial: Managing projects as complex social settings', Building Research \& Information Special Issue (2005), 33(6), 487-493.

Cherns, A. B. and Bryant, D .T. (1984) Studying the client's role in construction, Construction Management and Economics, Vol.2, 177-84.

Dainty, A.R.J. (2008) Methodological Pluralism in Construction Management Research. In Advanced Research Methods for the Built Environment (A Knight and L Ruddock Eds.), Blackwell Publishing, Oxford, pp1-12.

Gherardi, S. and D. Nicolini (2002) 'Learning the Trade: A Culture of Safety in Practice' Organization (9) 191-223.

Halstead, N., E. Hirsch and J. Okely (eds) (2008) Knowing How to Know: Fieldwork and the Ethnographic Present, Oxford: Berghahn.

Harris, M. (2007) 'Introduction: Ways of Knowing' in M. Harris (ed) Ways of Knowing, New Approaches in the Anthropology of Experience and Learning Oxford: Berghahn. 
Ingold, T. (2000) The Perception of the Environment, London: Routledge

IOSH. 2007. Summit meeting set to tackle fatalities, http://www.iosh.co.uk/index.cfm?go=specialist.news item\&aid=1399\&sgID=1)

Jordan, Brigitte (1996), "Ethnographic Workplace Studies and Computer Supported Cooperative Work". pp. 17-42 in The Design of Computer-Supported Cooperative Work and Groupware Systems. Dan Shapiro, Michael Tauber and Roland Traunmüller, eds. Amsterdam: Elsevier Science.

Marchand, T. (2003) 'A possible explanation for the lack of explanation: Or, "why the master builder can't explain what he knows': Introducing the information atomism against a "definitional" definition of concepts' in J. Pottier, A. Bicker and P. Sillitoe (eds) Negotiating Local Knowledge, London: Pluto.

Marchand, T. (2007) 'Crafting Knowledge: the role of "parsing and production" in the communication of skill-based knowledge among masons' in M. Harris (ed) Ways of Knowing, New Approaches in the Anthropology of Experience and Learning Oxford: Berghahn.

Mars, G. 2005 'Locating Causes of Accidents in the Social Organisation of Building Workers'. International Journal of Nuclear Knowledge Management, Vol. I, No.3, Spring 2005 pp. 255- 269

Martin, D. (2005) 'Communities of practice and learning communities: do bilingual coworkers learn in community?' in D. Barton and K. Tusting (eds) Beyond Communities of Practice: Language, Power and Social Context, Cambridge: Cambridge University Press.

McKay, S., Craw, M. and Chopra, D. (2006), Migrant workers in England and Wales: An assessment of migrant worker health and safety risks. Report for HSE by Working Lives Research Institute, London Metropolitan University, London.

Nicolini, D., Gherardi, S. Yanow, D. (2003), 'Introduction' in Davide Nicolini, Silvia Gherardi, Dvora Yanow (eds.) Organizational Knowledge as Practice. Armonk, NY: ME Sharpe, pp.3-31

O'Reilly, K. (2005) Ethnographic Methods, London: Routledge

Owen, E. (2007), Shock rise in site deaths down to language barrier, New Civil Engineer, 22 March 2007, p11.

Paap, K. (2006), Working Construction: Why white working-class men put themselves and the labour movement in harm's way. New York: Cornell University Press.

Pink, S. (2009) Doing Sensory Ethnography, London: Sage.

Pink, S. (ed) (2005) Applications of Anthropology, Oxford: Berghahn

Pottier, J. (2003) 'Negotiating Local Knowledge: An introduction' in J. Pottier, A. Bicker and P. Sillitoe (eds) Negotiating Local Knowledge, London: Pluto.

Rooke, J. A, Seymour, D. and Fellows, R. (2004) 'Planning For Claims: An Ethnography of Industry Culture', Construction Management and Economics, 22 (6), pp. 655-662.

Rooke, J \& L. Clark (2005), 'Learning, Knowledge and Authority on Site: a Case Study of Safety Practice', Building Research and Information, 33(6), pp.561-570.

Schatzki, T., K. Knorr-Cetina and E. von Savigny (eds) (2001) The practice turn in contemporary theory, London: Routledge.

Sillitoe, P. (2002) 'Participant Observation to Participatory Development Making anthropology work' in P. Sillitoe, A. Bicker and J. Pottier (eds). Participating in Development: Approaches to Indigenous Knowledge, London: Routledge. 
Strati, A. (2003) 'Knowing in Practice: Aesthetic Understanding and Tacit Knowledge' in D. Nicolini, S. Gherardi and D. Yanow (eds) Knowing in Organisations, New York: M.E. Sharpe Inc.

Sykes, A.J.M. (1969a) Navvies: their work attitudes. Sociology: 3, pp21-35.

Sykes, A.J.M. (1969b) Navvies: their social relations. Sociology: 3, 157-172.

Tutt, D., S. Pink, A. Dainty and A. Gibb (forthcoming), "'We've got our own

language": Adaptable Communication Practices of Migrant Workers in the UK Construction Industry', in S. Pink, D. Tutt and A. Dainty (eds.), Ethnographic Research in the Construction Industry. London: Routledge.

Wenger, E. (1998) Communities of Practice: Learning, Meaning, and Identity. Cambridge: Cambridge University Press.

Whyte, J.K., Ewenstein, B., Hales, M. and Tidd, J. (2007) Visual practices and the objects used in design. Building Research and Information, Vol.35, No.1, 18-27.

Yaneva, A. (2009) Made by the Office for Metropolitan Architecture: An Ethnography of Design. 010 Publishers, Rotterdam. 